\title{
Methods against Methods
}

\author{
Marc Stierand \\ NHTV Breda University of Applied Sciences, the Netherlands \\ Viktor Dörfler \\ University of Strathclyde, United Kingdom
}

Keywords: methods; creativity; innovation; problem-solving; systems view; lateral thinking; extraordinariness; master level knowledge;

\section{ABSTRACT}

This chapter intends to clarify some issues about the often misunderstood terminology of creativity and innovation methods. Following the train of thought outlined in this chapter, it is argued that neither creativity nor innovation is guided by a method. There are only methods against methods that can help the extraordinary individual to step faster and easier into a state of mind that is conducive to creativity, but which has no effect on whether the creative output becomes an innovation. In order to support this claim, three major reasons that seem to be responsible for making people believe that such methods for creativity and innovation exist are outlined here. Next, the chapter addresses the phenomenon of creativity and continues with a discussion on the systemic character of creativity and innovation. Finally it shows that there are no methods for creativity, but methods against non-creativity by explaining in particular how one of these methods against non-creativity works. What this chapter outlines here is a necessarily one-sided and partial view, aiming not to convince the readers of the correctness of the view, but rather to make them think by presenting one possible consistent approach.

\section{CREATIVITY AND INNOVATION}

Are there steps that, when followed, lead not only to a new idea (i.e. creativity), but also to a successful idea (i.e. innovation)? We do not think that there are, but we think that there are methods against methods that can help the creative individual to step faster and easier into a state of mind that is conducive to creativity. But there is still no connection to innovation, because whether an idea becomes an innovation is not decided by the creative individual, but, as we shall see later, by the perceptive value of this idea.

Outside the academic world innovation is often seen as enigma, as the work of a creative genius or as serendipity. However, this view is mostly dismissed by academics as unscientific, 
because its validity is very difficult to test. Therefore, academia has created a preference for seeing innovation as a continuous, rational, and purposive process (Nelson \& Winter, 1982; Rogers, 1962). Researchers interested in innovation often apply micro perspectives and frequently seem to be lost in thought trying to answer questions of explanation, prediction, and correspondence. This has led to a lack of understanding about the phenomenology of innovation, which we see as the foundation on which any explanation, prediction and correspondence should be built. Moreover, there is still the problem that we have to deal with creativity when we engage with the topic of innovation. Although many researchers acknowledge the link between creativity and in-novation, they just close creativity into a black box or go around in circles by trying to blueprint the creative process.

The problem about creativity is that we know it exists, but we do not know how it works. In other words, we do not know what the creative process looks like. We have never seen it. We have only seen the creative product that is the result of a person's creativity. Another widespread issue is linked to the creative individual. Many people think that everyone can be creative. But if this would be the case, why are there so few Mozart's and Shakespeare's? Our Western and postmodern society tends to equate equality with sameness and thereby neglects the creative extraordinariness of a few. Our society does not welcome outliers. In fact, we even cut off these tall poppies, because their talents naturally distinguish them from the rest of us. People can be equal, but they are not the same. Not everyone can paint like Matisse and not everyone can write like Goethe. Even if one could prove that all people start with the same genetic makeup for creativity from birth, not everyone will be able or will have the chance to develop a creative ability that can produce creations of the quality and influence as those of the aforementioned masters.

In order to support our arguments, we are going to outline our understanding of creativity and innovation and show how both phenomena are linked. Based on this outline we focus on the creative individual. We particularly draw on Gardner's conception of extraordinariness in order to illustrate that creating something new and valuable requires an individual with substantial knowledge and not just the ability to enter a state of mind that is conducive to creativity. Then we expand our discussion to the phenomenon of innovation by showing that innovations are not produced solely by an individual but require the socio-cultural world for validation and co-creation of the new value. At the end we look at de Bono's work on creativity methods.

What we want to present in this essay is our approach to creativity and innovation. This is a necessarily partial and one-sided approach, just as anyone else's. Conversely, we do not offer a comprehensive literature review; we are only covering the literature necessary to outline our position. Specifically, we do not engage with the issues of team dynamics, thus we disregard the sources aimed at encouraging creativity in organization and facilitating teams regardless whether those are supposed to be creative teams or not. We also limit our study of creativity to extraordinary performance; we do not engage with the creativity of people at below-expert knowledge level. Our argument is not directed towards a particular method or groups of methods, but rather we are questioning the idea of having methods for 
creativity/innovation. Thus this paper does not include description or comparison of various methods. There is one exception to this, a group of methods baring specific relevance to our argument; this group is outlined briefly to support understanding. We do not aim at convincing the readers that this is the only right way to address creativity and innovation, only that this is one possible way. By doing so, we would like to make the readers think more deeply about creativity and innovation. However, before doing so it is necessary to explain what we mean by creativity.

\section{UNDERSTANDING CREATIVITY}

Let us start explaining creativity through the notion of problem solving. Simon (1973) distinguished between ill-structured and well-structured problems and regards the first as a residual concept, which means that a problem is ill-structured when it is not well-structured. An ill-structured problem is one that is deficiently defined, whereas a well-structured problem possesses some or all of the following characteristics (Simon, 1973: 183):

1. There exist definite criteria to test the solution;

2. The initial problem state, the goal state and all intermediate states may be represented;

3. The transitions between the previous states can be represented;

4. The acquired knowledge can be represented;

5. The effects of the environment can be represented;

6. And a feasible amount of search and computing is required;

Simon, however, admitted that his proposed criteria for well-structured problems are vague and not completely definite, because there are many shades of definiteness along the way between ill- structured and well-structured problems. People were always fascinated by the idea of discovering nature's book of explanations in which they believe they can find the answer to how the human mind works. In the $17^{\text {th }}$ century, for example, the great French mathematician and philosopher René Descartes tried to find a universal method to solve problems. But, as Pólya (1957) remarks, Descartes failed to understand how the human mind solves problems in the first place. Over 300 years later Simon took on Descartes challenge and tried for most of his career to build what he called a General Problem Solver (GPS). The working principle of the GPS is very sensible: find what is identical in all problems, the common part, and use this as the base and then you only need to sort out the details that make the difference (e.g. Newell \& Simon, 1972). This is sensible in principle. But can you tell what the common part is in finding a cure for cancer and making great paella? Nothing has changed since Descartes, and we still do not know how the mind solves problems and especially ill-structured ones. The only thing we know is that the same in all ill-structured problem-solving is that the problem-solver sees things differently from how they are usually seen. In other words, the problem is solved through creativity. The reasons why we still do not know how the mind uses creativity, is simply because the part of thinking, which is responsible for seeing things 
differently, is non-algorithmic. This means that this part of thinking cannot be put into a finite sequence of instructions for solving a problem. De Bono $(1971,1994)$ calls this nonalgorithmic part of thinking lateral thinking or sometimes parallel thinking. The notion of lateral thinking can be easily grasped through explaining how good jokes work (Baracskai, 1998). In good jokes the joke teller takes us on a vertical way of thinking. Something like:

\section{A man and a friend are playing golf one day at their local golf course. One of the guys is about to chip onto the green when he sees a long funeral procession on the road next to the course. He stops in mid-swing, takes off his golf cap, closes his eyes, and bows down in prayer.}

This vertical way sets us on a way towards the obvious conclusion: probably the man stops playing golf, because he wants to be respectful towards the mourners. This is the essence of vertical thinking; there is a single outcome and the thinking converges towards it. But in a joke there is a jump out from the vertical storyline into a lateral direction. The obvious is rearranging to form a new order, to make new sense when we get to the punch line. In our example the friend says:

"Wow, that is the most thoughtful and touching thing I have ever seen. You truly are a kind man." The man then replies: "Yeah, well we were married 35 years."

If there were to be no new order it would not be a joke. Nobody would laugh. The reason why we laugh is because we understand that there is another way of thinking according to which the punch line is perfectly logical. It makes sense, but we would not have thought of it. We have now seen that creativity is highly anti-methodological in Feyerabend's (1993) sense and the new, the thing that astonishes us, that makes us laugh, or that makes us say "why did I not think of that before?", is a lateral detour. In other words, it is a discontinuity, a sudden change that is not usual in the given situation and that shows no obvious connection between the factors under consideration (de Bono, 1971). But with hindsight, and that might be the reason why people think that there are steps to produce new ideas, the lateral thinking is logical, which means that the new solution is obvious. However, there is again bad news for those who think that we should just do a bit of reverse engineering and follow back the lateral route to blueprint the steps the creator or joke teller took to see how creativity works. But unfortunately we have no evidence that the later explanation reflects the way how the creator or joke teller got to the novelty (Gladwell, 2005). Of course, saying that creativity is about seeing things differently, does not mean seeing in any different way. Only in ways that make sense, just no one has seen it before. Hadamard (1954), for example, investigated how new results are born in the field of mathematics, which is usually thought of as being completely logical. His investigation showed, among other things, that the creator requires deep knowledge and that the novelty is born in a flash of intuition. According to Hadamard, the first phase is the conscious hard work of trying to solve a problem followed by a kind of forgetting phase, which is a sort of unconscious continuation of the work. After that phase comes the sudden insight accompanied by a sense of certainty. At the end the mathematician proves the 
result on paper in full consciousness. We now have a reasonably solid explanation why there can be no methods for being creative: First, the creative jump cannot be seen in advance, but only retrospectively. And second, an algorithm cannot go into a place that cannot be seen. This is only possible through imagination and intuition. We now continue to outline the systemic character of creativity and innovation by referring to the link between creativity and innovation, the creatives, and idea creation and value creation. These aspects, as we will show, are reasons why we cannot apply steps for creativity and innovation.

\section{THE SYSTEMIC CHARACTER OF CREATIVITY AND INNOVATION}

\section{The Link between Creativity and Innovation}

Csíkszentmihályi $(1997,2006)$ speaks of two types of creativity: Creativity (with a capital C) and creativity (with a lower case c) as can be seen in the following figure. Creativity (with a capital C) is a system of three interrelated parts:the domain, the field, and the individual. The domain is the area in which the individual has chosen to work. Each domain has its specific rules, knowledge, tools, practices and values. The field, on the other hand, consists of the persons and institutions that judge the individual creator's quality of work. In other words, the field consists of the gatekeepers to the domain. The individual creator, in contrast, is influenced by her/his personal creativity (that is creativity with a lower case c) and by her/his specific genetic makeup, talent and experience (Figure 1).

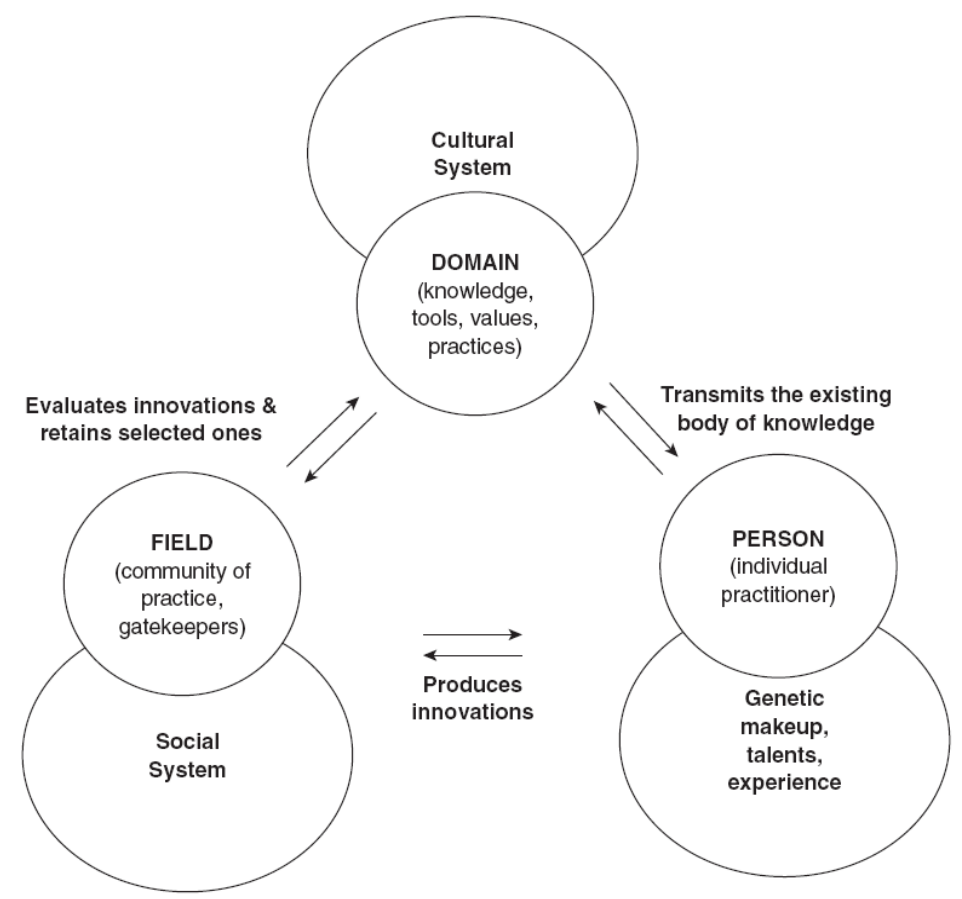

Figure 1: A Systems Model of Creativity. Source: Csíkszentmihályi (2006: 4) 
Hence, Creativity is concerned with changing or transforming an existing domain, whereas creativity is concerned with the actions or thoughts of a creative person that have the power to change or transform an existing domain. In other words, creativity is concerned with the creation of a new idea and Creativity is concerned with realizing a new value, that is, the successful innovation from the idea. This link between creativity and innovation can be expressed as a two stage heuristic process. The first stage is a creative process of solving an ill-structured problem in which the problem solver rearranges her/his existing knowledge in order to obtain a solution for the problem (Dörfler, 2004). The validation of the idea happens then in the network of gatekeepers. The second stage is concerned with how the idea is converted into a value. The validation of the new value is then executed by the field, which actually co-creates the value by promoting it to the domain (Figure 2).

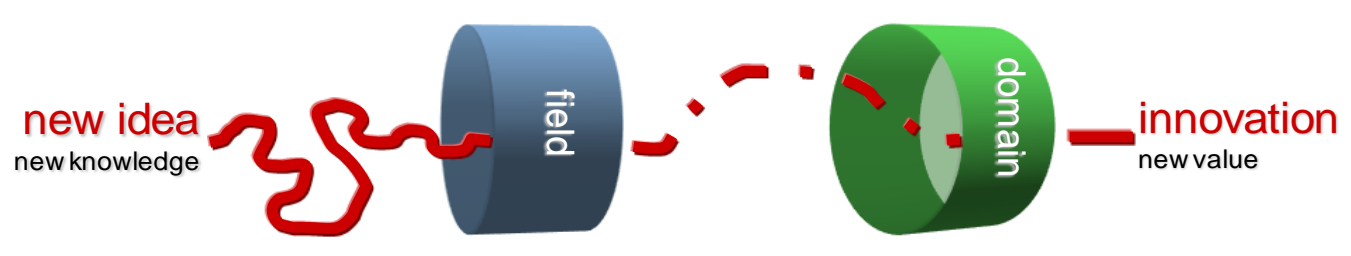

Figure 2: Heuristic Process of Innovation. Source: own figure

Going back about one century to the beginnings of innovation research tells us that the interest in innovation actually emerged from diverse branches within the social sciences. While these branches applied different background knowledge, they had the common intention to describe and give reasons for social changes. Anthropologists like Alfred Kroeber (1876-1960) and Ralph Linton (1883-1953), for example, explored cross-cultural diffusions of technical and social practices, which they called borrowing inventions. And sociologists like William Ogburn (1886-1959) explained social change as continuous cultural lag. The economist Joseph Schumpeter $(1911,1939,1947)$, however, is certainly acknowledged by many as the initiator of innovation research. He derived his ideas about innovation from his analysis of economic and social systems and many believe that his thoughts gave the impetus to recognize innovation as the crucial factor for economic progress and change. In his early work, he assumed that a company's size affects its ability to innovate and therefore smaller companies, while being more flexible, seem to be better positioned to innovate than larger and more bureaucratic companies. Later, though, he suspected that larger companies, in particular those with a monopolistic market power, might be better positioned to innovate than smaller firms, because of their power and because they often have better resources. Fundamentally, he saw innovations as waves of creative destruction that can revolutionize a whole market. This view challenged the status quo of capitalism at the time, because it rejected the view that capital- ism is about managing its existing structures and proposed that it actually is about destroying its existing structures in order to create new ones. This also meant that firms that can respond fast enough and can take hold of discontinuities are better positioned that firms that have difficulties to do so. Hence, innovation is therefore not the response to a wellstructured problem for which we are able to apply exact criteria that we can test and neither 
can we blueprint each single phase of the innovation process. Approaches that try to make us believe that this is possible just create an artificially validated process under a condition that Bessant and Caffyn (1997) termed continuous innovation. Under this condition, innovation is nothing more than a process of improvement that takes place in a framework of existing and known rules. Simply said, continuous innovation means doing things as usual, only better. This does not exclude significant changes but implies that changes occur within an established framework. Of course, continuous innovation is already a complex phenomenon, but research cannot ignore that innovation can also be influenced by discontinuous and chaotic conditions. Discontinuity can be a scary notion, because it is not an everyday event. Innovators are forced to experiment in order to accumulate new knowledge that can help them to keep track in an unpredictable world. During times of experimentation a so-called dominant design emerges that in some way predicts the most popular but not necessarily the most sophisticated trajectory of the future. The old trajectories, however, are still in place and normally undergo rapid improvements, which in turn sharpens the conditions for all actors. But many still see innovation as a linear and continuous process and argue that social (i.e. non-technological) and technological innovations are opposite ends of a continuum. Yet, social innovation just means that it is the result of accepting something new that changes the domain or creates a new domain. Consequently, every innovation, whether technological or non-technological, is also a social innovation, because the creative output has to pass social validation before it can become an innovation. This becomes obvious, if we look at how some great technical innovations that affected our lives. For instance, the first airplane was designed in 1903 but this had no effect on our lives whatsoever. The real impact of flying happened only in the 1960's, when we actually started to use airplanes to fly all over the world. We have now seen that innovation lies outside the influence of the creator, because it is a social validation of the creator's idea. It is obvious that there cannot be a method for controlling this social validation. This raises interesting questions regarding the responsibility of the innovator and also of various social institutions, but we do not engage with these in this chapter. We have now seen that innovation lies outside the influence of the creator, because it is a social validation of the creator's idea. It is obvious that there cannot be a method for controlling this social validation. This raises interesting questions regarding the responsibility of the innovator and also of various social institutions, but we do not engage with these in this chapter.

The term "social innovation" has been used throughout the literature to express a range of different ideas (Pol \& Ville, 2009). Taylor and Gabor were probably the first who mentioned the term explicitly .As a behavioural scientist, Taylor (1970: 70) argued that social innovation is a response to social needs by introducing, for example, an "innovative new school, a new way of dealing with poverty, a new procedure for resocializing delinquents, a new technique for rehabilitating the schizophrenic." Gabor (1970), on the other hand, saw social innovation as a tool to stimulate new arrangements in society such as new technologies or laws. Since 1970 it seems that a headless chicken run started to add yet another definition of social innovation to the literature and very often without improving the understanding of the concept. We are great believers in going back to the origins and, indeed, Taylor teaches us that his understanding of social innovation really explains a specific type of innovation; one that is expected to disrupt 
valued roles, identities, and skills of high complexity. In other words, social innovations may enrage and put whole communities to the test. Taylor offers here the amusing contrast with the invention of a new and better mousetrap. A new mousetrap will most likely be accepted quite quickly given sufficient advertising and right distribution. The reason is that accepting a new mousetrap involves no revolution in a person's identity or life style, whereas a social innovation requires a radical and revolutionary change of values and beliefs. And we all know how difficult that is.

After this detour into the social aspect of innovations, let us now look at the creatives themselves before we continue to discuss the topics of idea validation and value creation in detail.

\section{The Creatives}

Social psychologists have long argued for a link between extraordinary individuals and creativity (see e.g. Gardner, 1993; Guildford, 1950; Koestler, 1964; Osborn, 1953). More recently, however, they have begun suggesting that creativity is not exclusive to extraordinary individuals, but is a primary component of every human life. The problem is that situational factors, such as childhood and education, are very influential and finally decide whether a person is able to actualize on her/his creative potential. In other words, we face the same problem as earlier mentioned that, even if we assume that at birth all people start with the same genetic makeup for creativity, not everybody has the chance to exploit it. Gardner (1998: 11-12) distinguishes between four main types of extraordinary people: the master, the maker, the introspector, and the influencer. For example, he describes Wolfgang Amadeus Mozart as a master who typically "gains complete mastery over one or more domains of accomplishment; his or her innovation occurs within established practice." Sigmund Freud represents the maker, because a "maker may have mastered existing domains, but he or she devotes energies to the creation of a new domain." The introspector is represented by Virginia Woolf, because the "primary concern to this individual is an exploration of his or her inner life." And finally Mahatma Gandhi embodies the influencer, who "has as aprimary goal the influencing of other individuals." Further, it is important to note, argues Gardner, that individuals may comprise more than one type of extraordinariness. What most extraordinary people have in common is that they have often failed dramatically, but they have the ability to reflect on their failures and learn from them in such a way that they were able to clearly identify their strengths, exploit them, and thus turn defeats into opportunities. These lessons can be nicely linked to Schumpeter's description of the entrepreneur and the creative destroyer. For the early Schumpeter (1911) entrepreneurs were a small dynamic minority of agents that, in comparison to the rest of us, actively respond to changing environments and are able to create something new through overcoming internal and external resistance. This special breed of people, which Schumpeter (1947) later calls the creative destroyer, has the ability to successfully combine already available economic possibilities in completely new ways. Positive economic development is therefore achieved through innovations that have their source in the entrepreneurial spirit. Innovators are thus a kind of temporary monopolists, because they 
can exploit their position until imitators copy their ideas (Dörfler, 2010). Schumpeter (1911), however, strictly differentiated between the inventor and the innovator:

\begin{abstract}
"Economic leadership in particular must be hence distinguished from 'invention'. As long as they are not carried into practice, inventions are economically irrelevant. And to carry any improvement into effect is a task entirely different from inventing of it, and a task, moreover, requiring entirely different kind of aptitudes. Although entrepreneurs of course may be inventors just as they may be capitalists, they are inventors not by nature of their function but by coincidence and vice versa. Besides, the innovations which it is the function of the entrepreneur to carry out need not necessarily be any inventions at all" (Schumpeter, 1911: 88-89).
\end{abstract}

Schumpeter's distinction between the inventor and the innovator can be nicely linked to Csíkszentmihályi's dual flow between the field and the individual mentioned earlier, because both are needed to produce innovations. In other words, the field catches the idea of the inventor and co-produces the innovation by converting the idea into a new value by promoting it to the domain. Another way of arguing for a link between the extraordinary and creativity is the relation between creativity and domain knowledge. Here, Csíkszentmihályi draws two arrows between the individual and the domain. One goes from the domain to the individual signifying that the domain transfers knowledge to the individual. The other one goes from the individual to the domain signifying that the domain has accepted that the individual has created new knowledge that is valuable (i.e. that it is an innovation) and worth adopting. With regard to the link between domain and individual, Einstein (1956) stressed that even if the individual inherits some knowledge from the domain, the actual knowledge always originates in the mind of the individual. Prietula and Simon (1998) also talk about the extraordinary, but use the term expert. For them expertise goes far beyond just knowing a multitude of facts. In other words, they see a difference between people who know a myriad of facts and those few extraordinary individuals who can use their knowledge beyond the borders of reasoning to create new creative solutions. Johann Wolfgang von Goethe, for example, said that you can often hear amateur painters saying that their work is not finished yet. Goethe argued that they will never be finished, because they paint without awareness. The extraordinary or the master, on the other hand, knows from the first stroke what the final painting will look like (Goethe cited in Senge et al., 1999: 157). Goethe's example shows that the greatest distinction between amateur and extraordinary is the degree of awareness. By referring to Csíkszentmihályi's model, this means that the extraordinary creator has a deep awareness about the knowledge, values, tools and practices of the domain. Without this awareness a creation would have only a small chance to get accepted by the domain. Based on this train of thought we can now summarize that in order to create an innovation it needs an extraordinary person who is able to cope with the balancing act of using their knowledge beyond the borders of reasoning to create new creative solutions and being aware of the rules, knowledge, tools, practices and values of the domain. Now we are going to outline how a new idea is validated and how a new value is created. 
There is much disagreement about what qualifies a creation to be creative. This disagreement is certainly linked with the problem that the creative process itself (i.e. the process of coming up with a new idea) is unknown. One could argue that 'being creative' could also mean to come up with ideas that are widely considered 'useless' as long as the inventor went through a recognizable creative process. The Japanese Kenji Kawakami created the art of inventing objects that are practically useless by virtue of their disproportionate usefulness. He called his art chindogu. Zizek (2008) explains that chindogu objects must meet two criteria: they must be feasible to build, but they should be impractical in the sense that they cannot be marketed, because they would never receive the consent of the gatekeepers of the field to enter the domain. Consequently, the only possibility to judge whether an idea is creative or not, is to judge the value of the outcome of creativity. Amabile $(1988 ; 1996)$ and George (2007) define creativity as the creation of ideas that are both new and useful. In other words, there is a clear distinction between the creation of ideas and the creation of values. First, an idea is created, which, abstractly seen is always new knowledge, which is needed to solve the ill-structured problem. Only then can the new idea be pitched and transferred into a new value. If there is only a new idea and no value creation, the idea remains unknown, which means that the idea needs to be passed on by the value. The management literature speaks in this respect of the perceived newness or degree of innovativeness of the idea. Some authors formulate that an idea is creative when it is new and valuable and it is innovative when the idea has become realized. Others propose that the newness has to be validated in relation to the firm or market. Many years ago Zaltman, Duncan and Holbeck (1973) have introduced a broader concept of perceived newness, which they called relevant units of adoption. They argued that newness is context specific and evaluated along continua that describe the quality of newness. Of essence is that both the individual creator and the field require knowledge in order to produce an innovation and to validate its value. Hence, a person that aims at altering or changing a domain by his/her idea must convince the field of the value of the idea. The tricky thing with new ideas is that it is difficult to judge beforehand how new and valuable they will be perceived. Rogers (1962) introduced the concept of diffusion of innovations, which is the planned, but also spontaneous spread of ideas. Diffusion is a type of communication of new ideas, which, because the idea is new, involves uncertainty. Rogers (1962: 6) describes this uncertainty as "the degree to which a number of alternatives are perceived with respect to the occurrence of an event and the relative probability of these alternatives." Hence, information is used to overcome the lack of structure and predictability implied in uncertainty, because it is important that innovations are understood by the members of the field and domain. Understanding helps to limit the perceived risk and uncertainty. If a new idea is diffused and gets either adopted or rejected, this leads to a change in the social system. Consequently, whether a new idea becomes an innovation depends on the one hand how rule-breaking the idea is and on the other how compatible it is with the value system of the relevant unit of adoption. Innovations may disturb the sense-making of the domain and this is why innovation is often seen as dangerous, because it requires space and freedom from direction and control. In other words, the culture of the domain tends to remunerate individuals for their conformity 
and tends to punish those who challenge its culture. Let us discuss this two-way influence between the domain and its gatekeepers (i.e. field) and the individual by means of the concept of value systems. According to von Bertalanffy (1981: 13) "values are things or acts which are chosen by and are desirable to an individual or to society within a certain frame of reference." This means people within a value system are concerned with what is good and what is bad. Our individual value system can be described as muddled, because in the course of our lives, due to many different events, we change or reject values or adopt new ones. On the other hand, the value system of a domain is born from complex interactions of the value systems of its individual members and from the influence of other domains. The interesting thing is, however, that after the domain's value system is formed, it becomes independent of its members. This phenomenon can be explained by Hamel and Prahalad's (1994: 55-56) story about a group of monkeys. A number of monkeys were put in a cage. In the middle of this cage was a pole and at the top of this pole were bananas. As soon as the monkeys tried to get up to the bananas they received a cold shower. Now, the interesting part is that the monkeys very quickly learned not to go up the pole to get the bananas, because they would get a cold shower, which they obviously did not like. Later, all the monkeys were re-placed one by one and still no new monkey touched the bananas, because it became part of their group value system and each new monkey was "told" not to get the bananas. Again, we have shown that there is a difference between the perception of an individual and the perception of others. Therefore, it became now even clearer that there can be no method to make other people positively validate an idea and transform it into a new value. Now we are going back to creativity itself, which we have shown is a prerequisite for innovation, to explain its anti-methodological character.

\section{NO METHODS ALLOWED}

As a professional anarchist, Feyerabend $(1987,1993)$ rejects the use of any methods, as he observes that there is absolutely nothing that is present in all creativity but is absent in all other enterprises. Thus he declares that "Anything goes!" In his various books de Bono describes creativity as unexpected, non-linear, non-algorithmic, anti-methodical mode of thinking. This is what he calls lateral thinking to contrast it to convergent thinking, or parallel thinking to contrast it with vertical thinking. Yet, he offers a series of tools (used when needed) and habits (always present) for lateral thinking. Let us look at what these methods really do: de Bono (1973) offers a word, "PO", that goes beyond the true-false dichotomy; the "Six Thinking Hats" (de Bono, 1990) represent roles that can be used in brainstorming; the "Focus and Purpose" keeps one from forgetting the purpose; in the "Forward and Parallel" the forward thinking is a stepby-step inference along the path and the parallel thinking makes one stop and look around; the "Perception and Logic" emphasises that the logic is usually all right, but the perception should be improved for better outcomes; the "Values" serve as the basis for rejecting a logically correct solution, thus one should pay attention to what values are involved and who are affected by them; the "Outcome and Conclusions" are about not forgetting to consider the implications; the "Aims, Goals and Objectives" (AGO) similarly aim to prevent forgetting any of 
them; the "Consider All Factors" (CAF) suggests thoroughness instead of quick recipes; the "Other People's Views" (OPV) emphasises open-mindedness through considering who is affected (it can be considered a version of the stakeholder analysis); the "Alternatives, Possibilities and Choices" (APC) encourages both exploring and constructing alternatives; the "First Important Priorities" (FIP) focuses on selecting what really matters; the "Consequence and Sequel" (C\&S) urges exploring the consequences of the alternative actions; and finally the "Plus, Minus and Interesting" (PMI) is an assessment tool (de Bono, 1993: 63-150). Is this not infuriating? Why would someone who obviously understands the essence of creativity offer methods for it? Using Feyerabend we could say that anything goes but what you would normally do. These methods do not aim at making the creative process happen but rather at preventing us using the methods that we learned so well. De Bono's point is that we are so badly brainwashed that we would use the learned methods even subconsciously. Therefore his methods should not be seen as methods for creativity but rather as methods against noncreativity. Methods against methods.

Let us look closer at the example of PO. As mentioned above, de Bono (1973) offers PO as a word that goes beyond the true-false dichotomy. It is so to say the opposite of NO and NOT, without meaning YES. The essence of vertical or logical thinking is to make a selection by either accepting or rejecting something. As soon as we learn when to say no, we have learned how to use logical thinking. Or, as de Bono (1973: 196) says: "Logic could be said to be the management of NO." In contrast, lateral thinking can be explained as a restructuring and rearrangement of information that helps us to break out from rigid patterns we have learned from experience. To break out from these patterns de Bono offers the use of the word PO and therefore describes lateral thinking as the management of PO. Of course, both NO and PO are language tools, but they have totally different functions. By saying NO we give a judgment, whereas by saying PO we are anti-judgmental. By saying NO we think within our learned framework of reasoning, whereas by saying $\mathrm{PO}$ we think outside our framework. But how does PO work? As earlier said, PO is, like NO, a language tool, but one that we are not used to. Therefore, it can help us to break out from the safe and familiar environment of our language and way of thinking. We just do not use the word PO on a daily basis and thus we are not used to it. Because we are not used to PO, it can help our mind put together information in new ways even if these new arrangements of information are unjustified. In other words, PO can help liberate us from our mind by disrupting our established patterns of thinking. This means that we have in addition to the selective options of YES and NO used in logical thinking also the option of PO, which allows us to select, or better accept, an option that might seem totally illogical and even absurd. Let us refer here to an example given by de Bono (1971: 205-206). He provides the following statement to explain the use of PO: "PO water flows uphill if it is colored green." Most of us would probably say: "NO, water never flows uphill if it is colored green. In fact, water will never flow uphill!" But water can flow uphill. By adding a tiny amount of a particular sort of plastic, the water solidifies slightly with the effect that when we pour out this plastic-water mixture from a jug and then again hold the jug upright the water continues to flow out by climbing up the sidewalls of the jug. Is this not incredible? De Bono further suggests understanding the response to PO before we actually use PO. Why is that? In our common form 
of communication, when we use vertical thinking, we always give selective judgments about another person's statement. In other words, we either agree or disagree with what the other person has said. The same will happen when beginners try to use the word PO. We are so indoctrinated by the selective mechanisms of our language that we think the PO-statement is also a judgment. But it is not. This is the very essence of PO. Maybe it is helpful to picture PO as a sticky tape with which we can tape those possibilities that we would normally reject as being completely irrelevant, useless, illogical or impossible to realise. However, this does not imply that the PO-statement is a better alternative or even an alternative at all. In this sense PO is never judgmental and therefore it is a protection that allows following new ways and that can help us to use information in a provocative way. Moreover, PO can bring relaxation in situations where we stuck in the rigidity of thinking. It can make us smile, because we can formulate seemingly alien possibilities that seem so absurd that they can help us break the rigidity to see the problem from a different angle from which we might easier grasp a solution.

\section{CONCLUSION}

At the beginning we asked whether there are steps that, when followed, lead not only to a new idea (i.e. creativity), but also to a successful idea (i.e. innovation). We argued that there are no such steps, but that there are methods against methods that can help the creative individual to step faster and easier into a state of mind that is conducive to creativity. Then we identified a number of reasons why some people think that such steps exist. The first reason is that academia has created a preference for seeing innovation as a continuous, rational, and purposive process, because the fuzzy aspects of creativity are difficult to validate and cannot result in testable explanations, predictions, and correspondence. The second reason is that many academics close creativity into a black box or run around in circles trying to blueprint the creative process. We see this is as a problem, because on the one hand we cannot ignore that creativity is a prerequisite for innovation, but on the other hand we have to accept that nobody knows how creativity works. The only possibility that remains is therefore to come as close as possible to the phenomenon of creativity. The third reason is connected to the creative individual. Academia tends to assume that everyone can be creative and often rejects that a truly creative idea requires an extraordinary mind. This has probably created the strongest belief that steps exist that, when followed, bring us to the novum. In order to support these earlier mentioned reasons, we discussed the systemic character of creativity and innovation by particularly focusing on the link between creativity and innovation, the creatives, and how ideas are validated and how new values are created. Based on this discussion we concluded that creativity, and for that matter innovation, does not allow for methods. In other words, there are no methods for creativity, but methods against noncreativity. This claim was further supported by particularly focusing on the method "PO" as proposed by de Bono.

In this paper we outlined our particular view of creativity and innovation, more specifically one aspect of this view - our view on the impossibility of methods for creativity and innovation. 
This is a necessarily one-sided and limited view; but rather than providing a shallow and more inclusive overview of a topic we chose to immerse more deeply in this narrow interpretation. Our aim was not to convince the readers that our view is correct (let alone the only possible correct one) but to make them think more deeply about their own view of creativity and innovation. This is why we did not address areas that would be necessary for a more comprehensive discussion, such as the levels or types of creativity and especially the particular techniques/methods aimed at creativity and innovation.

There are also topics in this chapter that we marginally discussed, only to the extent needed for our present theme, some of which may be candidates for future research. Particularly we plan to engage more deeply into the social aspects of creativity and innovation including the questions of responsibility. We have further plans to research various aspects of creativity. In a project that we completed, Marc interviewed 19 of the greatest chefs in the world. In another, presently ongoing project, Viktor interviewed so far 15 grandmasters (people at the highest knowledge level), including 12 Nobel Laureates. We have further plans to carry out similar research projects in various creative industries. The rich qualitative data that we are collecting will be analysed in the framework outlined in this chapter.

\section{REFERNCES}

Amabile, T (1988) A model of creativity and innovation in organizations, Staw, B \& Cummings, L Research in organizational behaviour (Vol. 10), JAI Press, Greenwich, CT: 123-167.

Amabile, T (1996) Creativity in Context, Westview Press, Boulder.

Baracskai, Z (1998) Profi problémamegoldó (Master of Problem Solving), "Szabolcs-SzatmárBereg megyei Könyvtárak" Egyesülés, Nyíregyháza.

von Bertalanffy, L (1981) A Systems View of Man, Westview Press, Boulder, CO.

Bessant, J \& Caffyn, S (1997) High-Involvement Innovation Through Continuous Improvement, International Journal of Technology Management, 14(1): 7-28.

de Bono, E (1971) Lateral Thinking for Management: A Handbook, McGraw-Hill, London.

de Bono, E (1973) Po: Beyond Yes and No, Penguin Books, London, UK.

de Bono, E (1990) Six Thinking Hats, Penguin Books, London.

de Bono, E (1993) Teach Your Child How to Think, Penguin Books, London, UK.

de Bono, E (1994) Parallel Thinking: From Socratic to De Bono Thinking, Viking, Penguin Group, London.

Csíkszentmihályi, M (1997) Creativity, HarperCollins, New York, NY.

Csíkszentmihályi, M (2006) A Systems Perspective on Creativity, Henry, J Creative Management and Development (3rd edition), Sage, London: 3-17.

Dörfler, V (2004) Descriptive Model of Learning Capability, Descriptive Model of Learning Capability, Alexandria, Egypt. 
Dörfler, V (2010) Fit for Innovation, Jolly, A The Innovation Handbook: How to Profit from your Ideas, Intellectual Property and Market Knowledge, Kogan Page, London, UK: 150-153.

Einstein, A (1956/1984) The World As I See It, Kensington Publishing, New York, NY.

Feyerabend, PK (1987/2002) Farewell to Reason, Verso, New York, NY.

Feyerabend, PK (1993/2002) Against Method (3 ${ }^{\text {rd }}$ ed.), Verso, London, UK.

Gabor, D (1970) Innovations: Scientific, Technological and Social, Oxford University Press, Oxford.

Gardner, H (1993) Creating Minds, Basic Books, New York.

Gardner, H (1998) Extraordinary Minds, Phoenix, London.

George, J (2007) Creativity in Organizations, The Academy of Management Annals, 1(1): 439477.

Gladwell, M (2005) Blink: The Power of Thinking without Thinking, Penguin Books, London, UK.

Guildford, J (1950) Creativity, American Psychologist, 5: 444-454.

Hadamard, J (1954) The Psychology of Invention in the Mathematical Field, Dover Publications, New York, NY.

Hamel, G \& Prahalad, CK (1994) Competing for the Future, Harvard Business School Press, Boston, MA.

Koestler, A (1964) The act of creation, Macmillan, New York.

Nelson, R \& Winter, G (1982/2003) An evolutionary theory of economic change, Belknap Press, Cambridge.

Newell, A \& Simon, HA (1972) Human Problem Solving, Prentice Hall, Englewood Cliffs, NJ.

Osborn, A (1953) Applied imagination (revised ed.), Charles Scribner's Sons, New York.

Pol, E \& Ville, S (2009) Social innovation: Buzz word or enduring term?, The Journal of SocioEconomics, 38: 878-885.

Pólya, G (1957/1990) How to Solve It: A New Aspect of Mathematical Method, Penguin Books, London.

Prietula, M \& Simon, H (1998) The Experts in Your Midst, Harvard Business Review, JanuaryFebruary: 120-124.

Rogers, E (1962/2003) Diffusion of innovations (5 $5^{\text {th }}$ ed.), Free Press, New York.

Schumpeter, J (1911/1934) The Theory of Economic Development, Harvard University Press, Cambridge.

Schumpeter, J (1939/1961) Konjunkturzyklen, Vandenhoeck \& Ruprecht, Göttingen.

Schumpeter, J (1947/1976) Capitalism, Socialism and Democracy ( $5^{\text {th }}$ ed.), George Allen \& Unwin, London.

Senge, P, Kleiner, A, Roberts, C, Ross, R, Roth, G \& Smith, B (1999) The Dance of Change: The Challenges to Sustaining Momentum in Learning Organization, Doubleday Currency, New York, NY. 
Simon, HA (1973) The structure of ill structured problems, Artificial Intelligence, 4(3-4): 181201. https://doi.org/10.1016/0004-3702(73)90011-8

Taylor, J (1970) Introducing Social Innovation, Journal of Applied Behavioral Science, 6(1): 6977.

Zaltman, G, Duncan, R \& Holbek, J (1973) Innovations and organisations, John Wiley \& Sons, New York.

Zizek, S (2008) The Prospects of Radical Politics Today, International Journal of Baudrillard Studies, 5(1). http://www.ubishops.ca/baudrillardstudies/vol5 1/pf/v5-1-article3zizek pf.html 